Thorax (1976), 31, 565.

\title{
A simple cooling circuit for topical cardiac hypothermia
}

\author{
D.R. W H E E L D N, D. W. B E T H U N E, R. D. G I L L, \\ a n d T.A.H. E N G L I S H \\ Regional Cardiothoracic Unit, Papworth Hospital, Cambs CB3 8RE
}

\begin{abstract}
Wheeldon, D. R., Bethune, D. W., Gill, R. D., and English, T. A. H. (1976), Thorax, 31, 565-571. A simple cooling circuit for topical cardiac hypothermia. Rapid uniform cooling of the heart is the most important requirement of any method using local hypothermia for protection of the myocardium during open intracardiac surgery. We report the construction and operation of a recirculation cooling circuit comprising a reservoir, pump, and heat-exchanger for this purpose. It is operated by the perfusionist and can deliver up to 1 litre of fluid per minute at $4^{\circ} \mathrm{C}$ into the pericardium or interior of the heart. Advantages of the system include rapid cooling of the myocardium, simplicity of operation, and applicability to all routine cardiac surgical procedures.
\end{abstract}

Profound local hypothermia is a satisfactory method of protecting the myocardium from the effects of ischaemia during open intracardiac surgery (Griepp, Stinson, and Shumway, 1973; Cohn and Collins, 1974). The effectiveness of any technique based on this principle must be assessed by the rapidity with which the myocardium can be cooled and metabolism reduced. Rapid cooling implies a capacity for irrigating the pericardial cavity and the interior of the heart with large volumes of cold fluid. This report describes the construction and application of a simple recirculation cooling system which meets these requirements and which has been in routine clinical use for the last $2 \frac{1}{2}$ years.

\section{DESCRIPTION OF APPARATUS}

The cooling circuit was originally assembled from equipment already available in the department. The essential components are a reservoir, pump, heat-exchanger, and chiller which are capable of delivering up to 1 litre of fluid per minute at $4^{\circ} \mathrm{C}$. The circuit is illustrated diagrammatically (Fig. 1). Detailed specifications of the equipment used and the addresses of manufacturers are given in the Appendix.

The Sarns roller pump is fitted with silicone rubber tubing $(6 \mathrm{~mm}$ id) and provides the dual function of aspirating cold fluid from the pericardial cavity and pressurizing the circuit reser- voir. The reservoir consists of a 1-litre disposable plastic bag, and flow from this through the heatexchanger and into the pericardium is regulated by an adjustable air bleed attached to the top of the reservoir. The heat-exchanger is connected to a Churchill Thermocirculator primed with a mixture of $30 \%$ alcohol in water and maintained at $0^{\circ} \mathrm{C}$. A shunt line is included between input and output tubing to facilitate priming and initial cooling of the circuit; this also enables the temperature of fluid in the circuit to be kept at $4^{\circ} \mathrm{C}$ if flow input is temporarily interrupted during the operation. Flow delivery to the pericardium is measured by a disposable rotameter positioned after the heat-exchanger. The final $25 \mathrm{~cm}$ of both input and output tubing is silicone rubber $(4 \mathrm{~mm}$ id) as polyvinyl tubing becomes too rigid at low temperatures. A blunt-ended metal sucker with multiple side holes is attached to the end of the cold output (suction) tubing (Fig. 2). The myocardial and nasopharyngeal temperatures and the temperature of fluid delivered to the pericardium are measured with an Ellab recorder. Other temperatures measured continuously include the arterial return to the pump-oxygenator and the water input temperature to the bypass heatexchanger. The myocardial temperature probes (Fig. 3) were initially made by us from 21 gauge needles with a small thermocouple placed $2 \mathrm{~mm}$ from the tip of the needle. These are now available from Ellab and can be safely autoclaved. 


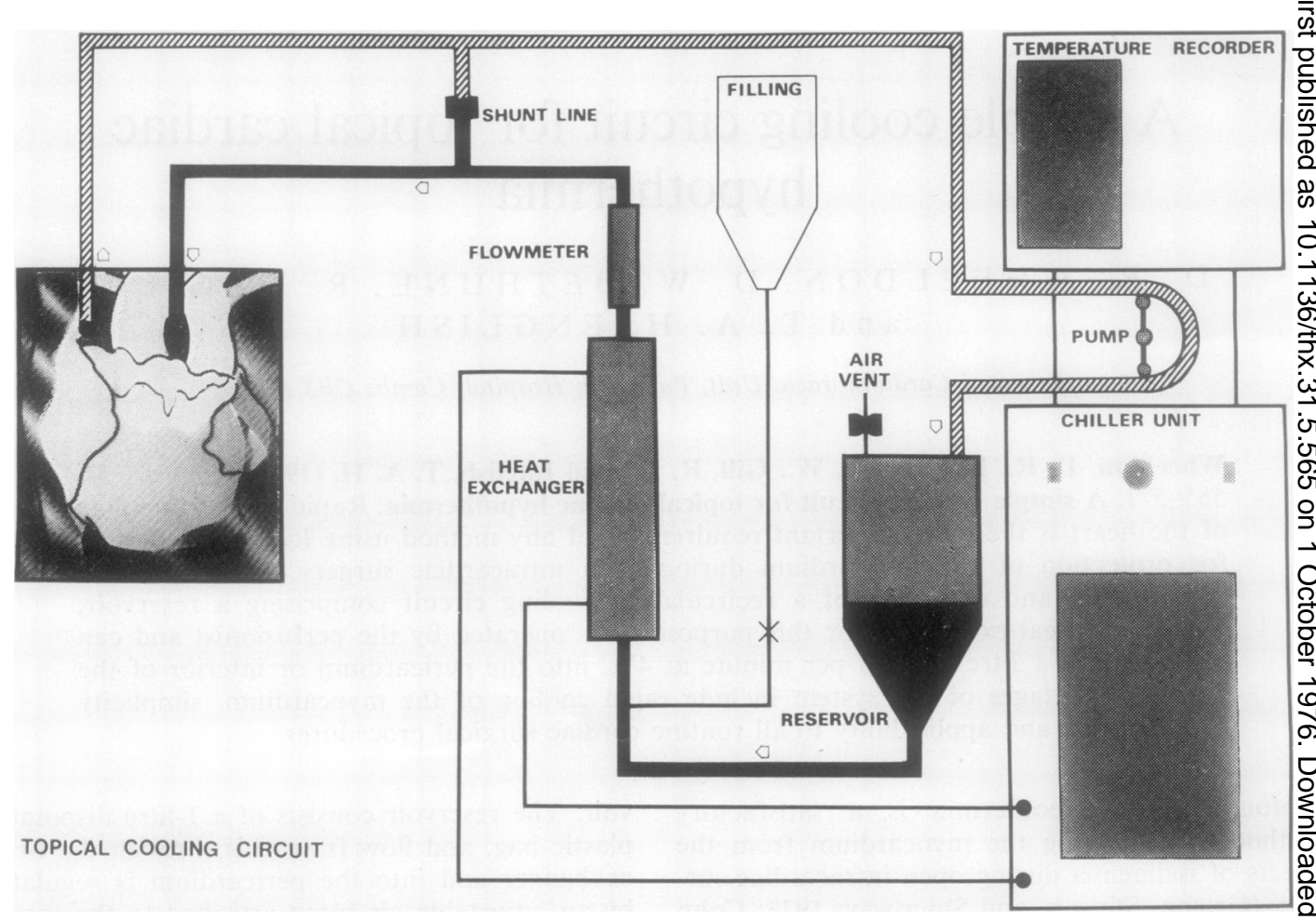

FIG. 1. Diagram of cooling circuit.

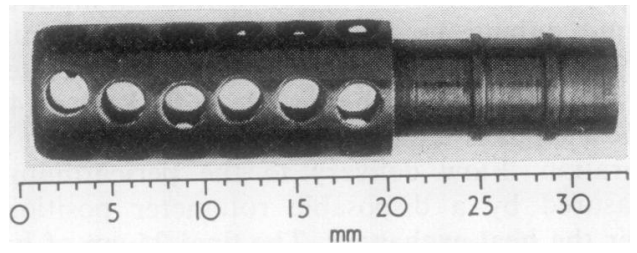

FIG. 2. Cold output sucker end.

The whole apparatus is mounted on a purposebuilt trolley which contains a work-surface for recording measurements and drawer space for spare connections, cannulae, and other items of equipment.

\section{OPERATION OF APPARATUS}

GENERAL The cooling system is assembled at the same time as the pump-oxygenator circuit. The thermocirculator is cooled to $0^{\circ} \mathrm{C}$ and connected to the heat-exchanger. The circuit is primed with 1 litre Hartmann's solution, which is cooled to

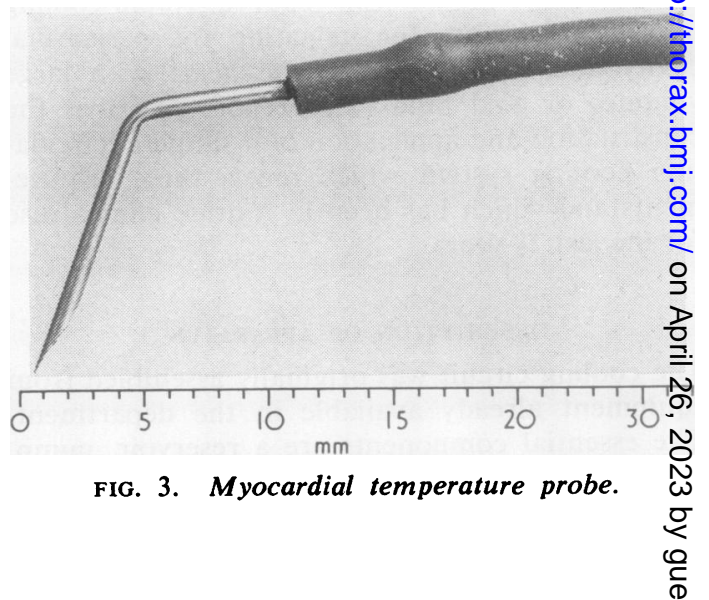

$4^{\circ} \mathrm{C}$ by circulation through the shunt line. Wifen the heart is ready for cannulation, the apparatus is positioned adjacent to the heart-lung mach ine so that the perfusionist has access to both setscop controls. The cool input and output lines secured to the operating table. 
Cardiopulmonary bypass with moderate hypothermia at a nasopharyngeal temperature of $32^{\circ} \mathrm{C}$ is used for most procedures lasting more than half-an-hour. The myocardial temperature probe is placed in the anterior part of the interventricular septum near the apex of the left ventricle, and intramyocardial temperature is recorded continuously. A left ventricular vent is inserted if indicated by the operative procedure and the aorta is clamped.

After blood has been aspirated from the heart, delivery of cold fluid into the pericardial cavity is started by unclamping the input and output lines and clamping the shunt line. The pump speed is increased and the air bleed adjusted to deliver a flow of $600-800 \mathrm{ml}$ per minute This is usually accomplished at a time when the cardiopulmonary bypass is relatively stable and it can therefore be attended to by the perfusionist without difficulty. At such high flows, precautions are necessary to minimize mixing of fluids between the cardiopulmonary bypass and cool circuits. Gentle suction on the vent is maintained to prevent blood spilling into the pericardial cavity and the tip of the cold sucker is positioned so that pericardial fluid does not flow into the heart. More complete immersion of the ventricles can usually be obtained by raising the head of the operating table $15^{\circ}$ and rotating it slightly towards the left. The speed of the Sarns pump is regulated so that it is normally aspirating fluid and air at a rate approximately $30 \%$ in excess of the volume of fluid input. The air in the suction line is released from the circuit via the adjustable air bleed on the top of the reservoir. This makes the system largely self-regulating and enables the surgeon to adjust the level of cold fluid in the pericardium by simply lowering the position of the cool sucker. This temporarily increases the volume of fluid returned by the sucker to the reservoir until air is once more entrained through the multiple side holes in the cool sucker end and a new balance is established.

At an early stage of the operation the vent suction is switched off and large volumes of cold fluid are temporarily diverted via the flow input into the interior of the heart. The establishment of a cooling gradient from both the endocardial and epicardial surfaces is most important, particularly in the presence of hypertrophied ventricles. After several minutes the cold input is returned to the pericardial cavity and the interior of the heart is aspirated with the discard sucker before vent suction is recommenced. When the intramyocardial temperature has reached $10^{\circ} \mathrm{C}$ the cold input is reduced to $200 \mathrm{ml}$ per minute. Systemic rewarming is begun at an appropriate time towards the end of the operation and cold perfusion of the pericardial cavity is discontinued as the chambers of the heart are allowed to fill with blood before release of the aortic clamp. The operating table is levelled.

The heart warms rapidly with normothermic coronary perfusion and, after residual air has been evacuated, defibrillation is attempted. This can usually be accomplished within three minutes of release of the aortic clamp. Supportive bypass is continued for at least another 10 to 15 minutes, depending on the duration of ischaemic arrest. During this period the left atrial pressure is maintained just high enough for ventricular ejection, and hence pulsatile coronary perfusion, to take place. Bypass is then discontinued in the usual way.

SPECIAL SITUATIONS The apparatus described is used routinely for all cardiac operations except those such as repair of simple atrial septal defect or pulmonary valvotomy, when the duration of anoxic arrest is less than 15 minutes. With experience, various minor procedural modifications have been found appropriate for different operations.

Aortic valve replacement The technique was first used by us for aortic valve surgery and the described procedure is followed. Initially, in an attempt to minimize the rewarming effect of blood returning to the left side of the heart, we used separate caval cannulation and occlusion of the cavae with snares during bypass. We have now demonstrated that a single atrial cannula is equally effective and use this in the interests of simplicity.

The right or superior lip of the aortotomy incision is retracted laterally to the pericardium by a single stay-stitch, and the end of the cold suction line is placed between the aortic root and the superior vena cava. The cold input line lies free in the pericardial cavity adjacent to the left atrial appendage. With the head of the table raised and slight rotation to the left, excellent covering of both ventricles is obtained throughout the operation. The interior of the left ventricle is always thoroughly irrigated with cold fluid after excision of the aortic valve.

Mitral valve procedures During mitral valve surgery immersion of the ventricles beneath the cold fluid is more difficult to achieve, and in the pre- 
sence of a small left atrium it is impossible to cover the right ventricle without simultaneous overflow of pericardial fluid into the atriotomy. We therefore augment initial cooling of the heart by infusing Hartmann's solution at $4^{\circ} \mathrm{C}, 10 \mathrm{ml}$ per kilogram body weight up to a maximum of $500 \mathrm{ml}$, into the aortic root under pressure as soon as the aorta is clamped. This fluid is aspirated into the cardiopulmonary bypass circuit by the vent and coronary suction and forms part of the pump-priming volume. After the left atrial incision has been made, a modified cold input line, consisting of a $10 \mathrm{~cm}$ length of Silastic tubing with multiple perforations along one side, is placed to deliver a spray of cold fluid over the right ventricle. If the mitral valve is to be replaced, the interior of the heart is flushed out with cool fluid after the valve has been excised. Immersion of the left ventricle beneath the pericardial fluid level for the remainder of the procedure is obtained by rotating the table to the left and placing the cold sucker end between the inferior vena cava and the lower end of the left atrial incision.

Double valve replacement If both aortic and mitral valves require attention, the aorta is opened first and the heart is cooled by immersing both ventricles beneath the pericardial fluid level while the aortic valve is excised. The interior of the heart is flushed with cold fluid and then the fluid level is temporarily lowered while the mitral valve procedure is accomplished. The left atrium? is closed and the cold fluid level is raised again while the aortic valve is inserted.

Congenital heart surgery The technique has beend used for myocardial protection during the repaito of a wide range of congenital lesions. No specia? modifications are required, and rapid cooling of the myocardium is usually obtained because of the relatively small cardiac muscle mass.

\section{RESULTS}

Temperature charts during typical operations fo $\vec{E}$ aortic and mitral valve replacement are showrir (Figs 4 and 5). 'The beneficial effect of additionak cooling from the endocardial surface is clearly? demonstrated, as is the effect of a preliminary aortic root flush during the mitral valve operation? In both procedures the intramyocardial tempera? ture was reduced to less than $15^{\circ} \mathrm{C}$ within 1 minutes of aortic clamping. The rapidity with which the heart warms once coronary perfusion iş re-established is also clearly illustrated.

After rewarming, the heart sometimes begins to beat spontaneously, but in most cases defibrillation is necessary. In no instance has the heart failed to defibrillate successfully, and ischaemic contracő ture of the left ventricle (Cooley, Reul, an\$ Wukasch, 1972) has never been encountered. $\overrightarrow{0}$

In the first 200 operations in which the cooling circuit was used, the duration of cardiac ischaemiag

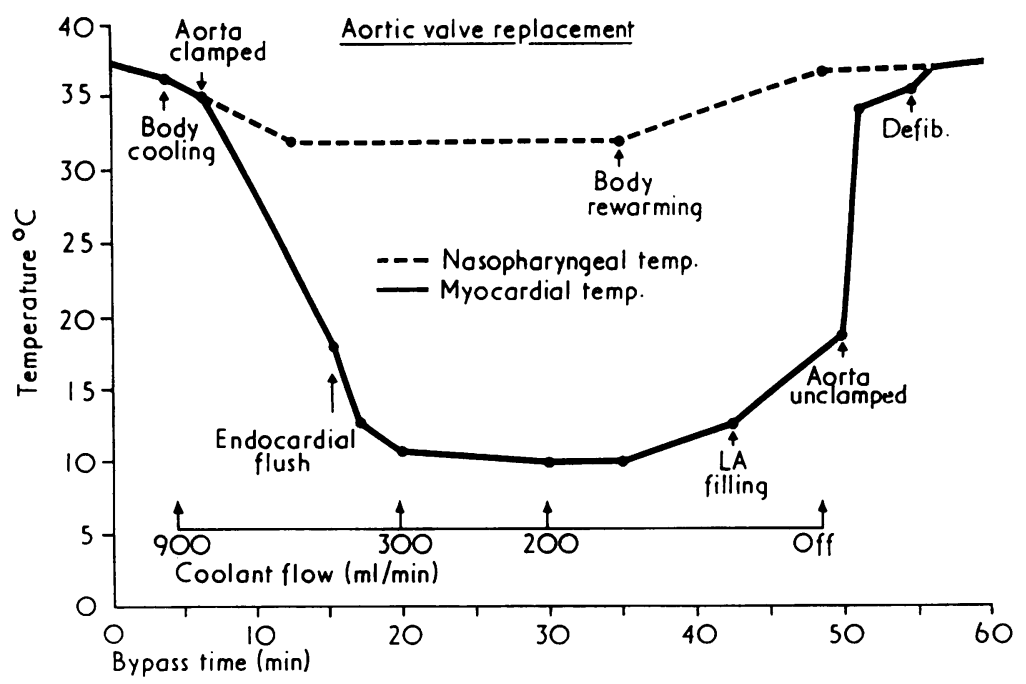

FIG. 4. Myocardial and nasopharyngeal temperatures during aortic valve replacement. 


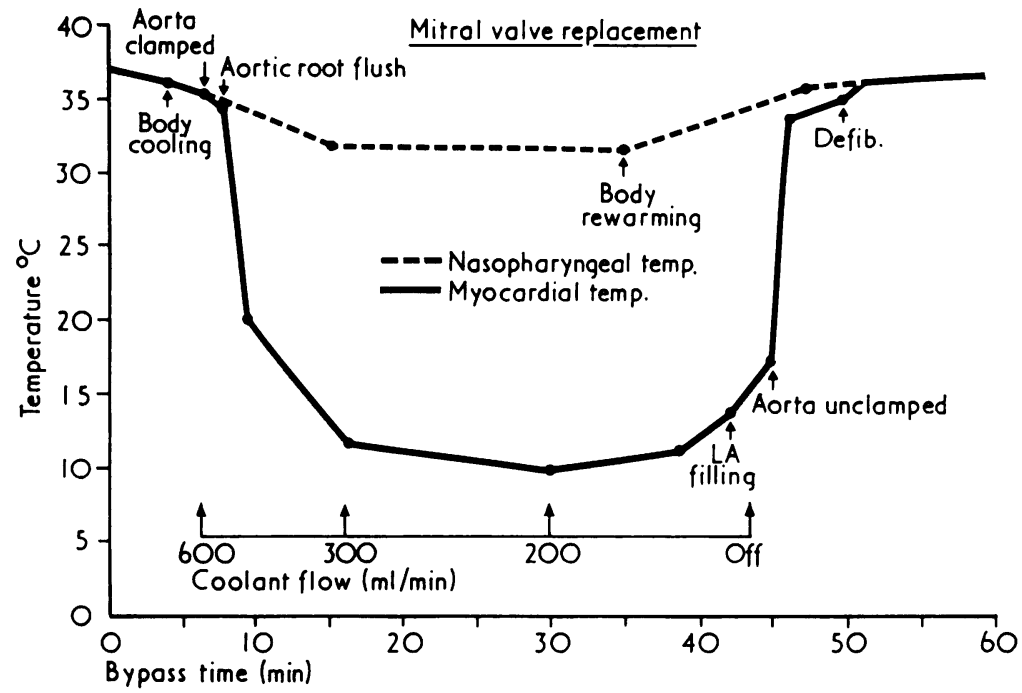

FIG. 5. Myocardial and nasopharyngeal temperatures during mitral valve replacement.

varied from 20 to 153 minutes with a mean of 67 minutes. The mean myocardial temperature during ischaemia was $14^{\circ} \mathrm{C}$. The operations performed included 109 aortic valve replacements (four with replacement of ascending aorta); 37 mitral valve replacements; 29 operations for congenital lesions; 14 mitral and aortic valve replacements; and 11 miscellaneous operations. There were five hospital deaths and four late deaths. A detailed analysis of these results, including a study of postoperative electrocardiographic changes, will form the basis of a separate report.

\section{DISCUSSION}

Credit for the successful clinical application of topical hypothermia for protecting the myocardium during elective anoxic arrest belongs to Shumway and his colleagues at Stanford University. In 1964 they were able to report a series of 120 consecutive cases with an early mortality of only $3.3 \%$ (Hurley et al., 1964), and their experience with this technique is now extensive. Their method comprises irrigation of the pericardial cavity with ice-cold saline, which is then discarded, delivered at a flow rate of approximately $100 \mathrm{ml}$ per minute by a standard intravenous infusion and augmented by copious lavage of the interior of the heart with cold saline (Griepp et al., 1973).
The simplicity of such a system has much to commend it but it involves refrigeration of large volumes of fluid. This presented a problem in our own department but the main reason we were prompted to develop a recirculation cooling circuit was in order to obtain the most rapid and uniform cooling of the heart possible. This implied the necessity for maintaining a large cooling gradient between the pericardial fluid and the myocardium, particularly at the beginning of the operation, and suggested the need for a system capable of providing larger volumes of cold fluid than could be delivered by simple gravity feed through an intravenous infusion set. We now feel confident in our ability to cool even the most hypertrophied hearts to $15^{\circ} \mathrm{C}$ within 10 minutes of aortic clamping. In this respect we believe it is important to measure myocardial temperature rather than to rely on clinical impression, as only in this way can the efficacy of a particular cooling method be assessed. There may be wide variations in myocardial temperatures measured simultaneously from the posterior wall of the left ventricle, the anterior wall of the right ventricle, and the interventricular septum. The latter is undoubtedly the most difficult area to cool in patients with hypertrophied left ventricles, and this is why we normally place the thermocouple in this position.

An efficient suction system in the cooling circuit is essential because of the high flows of cold 
fluid delivered to the pericardium. Inadvertent mixing of pericardial fluid with cardiotomy suction or vent return is of less consequence if Hartmann's solution rather than normal saline is used. We keep a separate fluid record for the cooling circuit although attention is soon drawn to significant mixing between it and the bypass circuit by changes in the level of fluid in the cool circuit reservoir.

The apparatus described can be used for all types of cardiac operations. Our own experience with its use in coronary artery surgery has been limited, but Griepp and colleagues (1975) have published encouraging results using the Stanford technique of topical hypothermia for this purpose. Tyers et al. (1974) have reported experimental evidence demonstrating that profound myocardial hypothermia can be achieved with a single aortic root infusion of Ringer's lactate at $4^{\circ} \mathrm{C}$, and it has seemed reasonable to enhance myocardial cooling by using this technique when the operation being undertaken does not allow adequate immersion of the heart beneath the pericardial fluid. In those patients who have had previous cardiac operations, it is necessary to free pericardial adhesions completely in order that satisfactory cooling of all aspects of the heart can be obtained. Entry into the pleural spaces means that these will need to be filled with cold fluid as well as the pericardium.

The apparatus is simple to operate and economical to run. It provides a relaxed and bloodless operating field which offers perfect conditions for surgery. Problems related to the cannulation and separate perfusion of the coronary arteries are avoided and damage to platelets and other blood constituents is less because of reduced coronary suction. Because of the rapidity with which the heart can be cooled, we believe that this is a satisfactory method of myocardial preservation for all forms of intracardiac surgery.

\section{REFERENCES}

Cohn, L. H. and Collins, J. J., Jr. (1974). Local cardiac hypothermia for myocardial protection. Annals of Thoracic Surgery, 17, 135.

Cooley, D. A., Reul, G. J., and Wukasch, D. C. (1972). Ischemic contracture of the heart: 'stone heart'. American Journal of Cardiology, 29, 575.

Griepp, R. B., Stinson, E. B., Oyer, P. E., Copeland, J. G., and Shumway, N. E. (1975). The superiority of aortic cross-clamping with profound local hypothermia for myocardial protection during aorta-coronary bypass grafting. Journal of Thoracic and Cardiovascular Surgery, 70, 995.

Griepp, R. B., Stinson, E. B., and Shumway, N. E.
(1973). Profound local hypothermia for myocaf dial protection during open-heart surgery. Journat of Thoracic and Cardiovascular Surgery, 66, 73를

Hurley, E. J., Lower, R. R., Dong, E., Jr., Pillsbury R. C., and Shumway, N. E. (1964). Clinicas experience with local hypothermia in elective cardiac arrest. Journal of Thoracic and Cardid? vascular Surgery, 47, 50.

Tyers, G. F. O., Hughes, H. C., Jr., Todd, G. JWilliams, D. R., Andrews, E. J., Prophet, G. Aç and Waldhausen, J. A. (1974). Protection from ischemic cardiac arrest by coronary perfusio with cold Ringer's lactate solution. Journal of Thoracic and Cardiovascular Surgery, 67, 411. $\frac{\overrightarrow{\mathrm{c}}}{\mathrm{c}}$

APPENDIX

EQUIPMENT FOR MYOCARDIAL COOLING SYSTEM

Thermocirculator

Churchill Model 05/CTC VM

With the following modifications:

(1) Reservoir capacity increased to $2 \cdot 51$

(2) Override switches to bypass pump cut out Churchill Instrument Co Ltd, Walmgate Roas Perivale, Middx.

\section{Fluid flow meters}

Disposable FAH $/ 700$ W.

Autoclavable at $15 \mathrm{psi} / 15 \mathrm{~min}$

Medimec, 22 Altembury Gardens, London SW1

\section{Pump}

Any roller pump having a minimum output cap city of $1.51 / \mathrm{min}$.

Air flow regulator (needle valve)

AC 1477

AC 1479

AC 1481

Connector $O D \stackrel{8}{3}$

$4.75 \mathrm{~mm}$

$7.93 \mathrm{~mm}$

$12.70 \mathrm{~mm}$

Autoclavable at $15 \mathrm{psi} / 15 \mathrm{~min}$

Enots Ltd, Box 288, Aston Brook Stred Birmingham.

A gate clamp with a fine thread is also suitabite but provides less control.

\section{Heat exchanger}

Any cardiopulmonary heat-exchanger with a pepformance factor better than 0.5 at a flow of $p_{5}$ litres per minute with a coolant flow of 10 litres per minute. This includes most adult size tubu通r and annular stainless steel heat-exchangers. 


\section{Tubing}

$6.4 \mathrm{~mm} \times 11.0 \mathrm{~mm}$ silicone rubber for the circuit on polycarbonate connectors (all autoclavable at $15 \mathrm{psi} / 15 \mathrm{~min}$ ). The table lines are $6.4 \mathrm{~mm}$ PVC sterilized with the rest of the bypass lines. The final $25 \mathrm{~cm}$ of both input and output tubing is silicone rubber $6.4 \mathrm{~mm} \times 4.0 \mathrm{~mm}$. We mount a perforated sump sucker (Fig. 2) on the end of the suction tube. Sump sucker obtainable from:

Bio Med Engineering Ltd, 1 Headlands Road, Liversedge, West Yorkshire.

\section{Reservoir}

Travenol 1 litre collapsible reservoir (5M0902). A reservoir with a capacity of $1 \cdot 5-2 \cdot 0$ litres with two ports at the bottom and two at the top is under development. One of the many rigid cardiotomy reservoirs would be even better except that it would add about $£ 10$ to the cost of the circuit.

\section{Temperature monitoring}

Continuous 6-channel recorder (Ellab), but any temperature monitoring instrument would do. Suitable probes are available from:

Ellab A/S, Krondalvej 9, Copenhagen, DK-2610 Rodvrk, Denmark.

Requests for reprints to: Dr. D. W. Bethune, FFARCS, Cardiothoracic Surgical Unit, Papworth Hospital, Papworth Everard, Cambridge CB3 8RE. 